\title{
Grape Seed Procyanidins Improve Diabetic Symptoms in Mice with Strep- tozotocin-Induced Diabetes
}

\author{
Sheng-Chuan Hsi ${ }^{\#, 1}$, Yuan-Ping Kao ${ }^{\#, 2}$, Pao-Yuan Wang ${ }^{2}$, Hong-Ming Chao ${ }^{1}$, Chung-Hsiung \\ Huang ${ }^{1}$, Hang-Seng Liu ${ }^{3}$, Li-Jane Shih ${ }^{3}$, Johannes Scheng-Ming Tschen ${ }^{4,5}$, Ching-Ling Lin ${ }^{6}$ and \\ Yung-Hsi $\mathrm{KaO}^{*}, 2$
}

\author{
${ }^{I}$ Department of Surgery and ${ }^{3}$ Department of Joint Laboratory, Taoyuan Armed Forces General Hospital, Taoyuan, \\ Taiwan \\ ${ }^{2}$ Department of Life Sciences, College of Science, National Central University, Jhongli City, Taoyuan, Taiwan \\ ${ }^{4}$ Department of Life Sciences, National Chung-Hsing University, Taichung City, Taiwan \\ ${ }^{5}$ Department of Life Science, Mingdao University, ChangHua, Taiwan \\ ${ }^{6}$ Department of Endocrinology and Metabolism, VIP Health Management Center, Cathay General Hospital, Taipei, \\ Taiwan
}

\begin{abstract}
Grape seed procyanidins (GSPCs) are bioflavonoid polymers that have been shown to have health benefits. We assessed the antidiabetic effect of GSPC in mice. Mice with streptozotocin(STZ)-induced diabetes were orally or intraperitoneally administered saline or 40-100 mg GSPC/kg BW daily for 7-10 d. We monitored body weight, blood glucose levels, amounts of food and water consumed, and amounts of urine and feces excreted. On the final day, we analyzed plasma chemistry and found that GSPC, but not structurally related monomers (e.g., catechin and epicatechin), reduced the glucose levels, food and water intake, and urine and feces excreted, all of which had increased due to STZ administration. This suggests a procyanidin-dependent effect of grape seed polyphenols on diabetes. Oral administration of GSPC was less effective within $9 \mathrm{~d}$ than was intraperitoneal administration of GSPC, suggesting that the effect is routedependent. The decrease in diabetic blood glucose levels was reversible; when GSPC administration was stopped, glucose levels rose. However, although pretreatment with GSPC for $7 \mathrm{~d}$ did not completely prevent STZ-induced diabetic effects, it rapidly reduced them. Treatment with GSPC reduced fasting glucose levels and improved glucose tolerance in STZtreated mice, in addition to decreasing STZ-stimulated levels of plasma triglyceride and cholesterol, creatinine, uric acid, and alkaline phosphatase activity. Moreover, GSPC suppressed the reduction in pancreatic islets and the decrease in plasma insulin hormone levels caused by STZ. Our findings indicate that GSPC improves hyperglycemia, polydipsia, polyuria, and polyphagia in mice with STZ-induced diabetes.
\end{abstract}

Keywords: Grape, diabetes, insulin, mice, procyanidins.

\section{INTRODUCTION}

Diabetes is commonly associated with obesity, cardiovascular disease, hypertension, high cholesterol, retinopathy, renopathy, and neuropathy [1]. The economic costs, prevalence, morbidity, and mortality associated with prediabetic conditions and diabetes are high [2-9]. The onset of diabetes is characterized by increased blood and urine glucose levels, excessive urination, thirst, hunger, and weight loss, all of which are regulated by genetic, endocrine, metabolic, pharmacological, environmental, and nutritional factors [1]. Accordingly, understanding how specific nutrients affect diabetic symptoms could help prevent the onset and progression of diabetes and associated diseases in humans.

*Address correspondence to this author at the Department of Life Science, College of Science, National Central University, Jhongli City, Taoyuan 32054, Taiwan; Tel: (886)-3-4260839; Fax: (886)-3-4228482;

E-mail:ykao@cc.ncu.edu.tw

${ }^{\#}$ These Authors contributed equally to this work.
Grape seed procyanidins (GSPCs) are a family of bioflavonoid polymers [10] that were once known as "vitamin P" [11]. GSPCs have unique chemical structures comprising dimers or trimers of catechin and (-)-epicatechin (EC) and are found in red wine and grape seeds [10]. A number of studies have indicated that they have a variety of health benefits due to their antibacterial, antiviral, anticarcinogenic, anti-inflammatory, and vasodilatory actions [10]. Further, procyanidins restore postischemic function in isolated rat hearts [12], stimulate the activities of enzymes, such as tyrosine kinases and phosphoinositide kinases [13-14], may prevent human metabolic syndrome [15], and possess antioxidant and free radical-scavenging activities [16-18]. Although recent studies have shown that oral administration of pharmacological doses $(250 \mathrm{mg} / \mathrm{kg}$ body weight $[\mathrm{BW}])$ of procyanidin-containing red wine and white wine extracts over a long period of time (6 wk) have an antidiabetic effect on Wistar rats with streptozotocin (STZ)-induced diabetes [19, 20], it was not clear from the results if procyanidin has a preventative effect on diabetic glucose levels or if it acts antidiabetically in mice. Further, it is unclear whether any of 
the in vivo effects of procyanidins are dependent on the duration of treatment and the route of administration.

In this study, we used mice with STZ-induced diabetes to assess possible effects of GSPC on diabetic symptoms (e.g., blood glucose and insulin levels, food intake, water consumption, body weight gain, and urine and feces excretions). We also investigated whether GSPC prevents increased blood glucose levels after STZ administration, and whether the effects of GSPC depend upon the route of administration.

\section{MATERIALS AND METHODS}

\section{Chemical Reagents}

GSPCs isolated from grape seed (Vitis vinifera) was a gift from Jaden polytechnic (Greer, SC, USA); the average percentage of polyphenolic compounds was $98 \%$, as established by the vanillin-hydrochloric acid method. Other materials (e.g., STZ, sodium citrate, glucose, (+)-catechin, EC, and gallic acid) were purchased from Sigma-Aldrich (St. Louis, MO, USA) unless otherwise noted.

\section{Animals and Induction of Experimental Diabetes}

Male ICR mice were obtained from the National Taiwan University Animal Center (Taipei, Taiwan). The mice were approximately $5 \mathrm{wk}$ of age and weighed 18-20 g. The animals were maintained at an ambient temperature of $25 \pm 1{ }^{\circ} \mathrm{C}$, $50 \%-60 \%$ humidity, and a photoperiod of $12 \mathrm{~h}$ light and $12 \mathrm{~h}$ darkness. Mice were given free access to a standard rodent chow diet (Hardwood Laboratory Bedding, Taipei, Taiwan) and water unless otherwise noted. Animal experimental protocols were reviewed and approved by the Laboratory Animal Ethics Committee, National Central University, Jhongli, Taiwan. Following the method reported by Junod et al. [21], diabetes was induced in mice that had fasted for $1 \mathrm{~d}$ by a single intraperitoneal (ip) injection of STZ (75 mg/kg BW) in $0.1 \mathrm{M}$ sodium citrate buffer $(\mathrm{pH} 4.5)$. Diabetic animals with hyperglycemia $(\sim 300 \mathrm{mg} / \mathrm{dL}) 3-7 \mathrm{~d}$ after the injection of STZ were used in the experiments unless otherwise noted.

\section{Experimental Treatments}

Mice with STZ-induced diabetes were divided into several groups of five mice each. In the control group, mice with STZ-induced diabetes were administered saline, while in the treatment group, mice with STZ-induced diabetes were ip injected daily with GSPC. Normal mice were ip injected daily with or without GSPC for comparison. For the dose-dependent experiments, diabetic mice were ip injected daily with approximately 40 or $80 \mathrm{mg}$ of GSPC/ $\mathrm{kg} \mathrm{BW}$ for the indicated time period in accordance with a method described by Kao et al. [22]. To assess the preventative effect of GSPC on diabetes, normal mice were daily pretreated with $\sim 80 \mathrm{mg}$ of GSPC/kg BW for $7 \mathrm{~d}$ or were untreated. After $1 \mathrm{~d}$ of fasting, animals were singly ip injected with or without STZ in the presence or absence of $\sim 80 \mathrm{mg} \mathrm{GSPC} / \mathrm{kg}$ $\mathrm{BW}$ for an additional $10 \mathrm{~d}$. For experiments to study whether the effect of GSPC is route-dependent, diabetic mice were given $90-100 \mathrm{mg}$ of GSPC/kg BW orally or by an ip injection daily for $10 \mathrm{~d}$; GSPC was dissolved in water for oral administration and in sterile saline for the ip injection.

During the experimental period, the body weight, blood glucose levels, and amounts of food and water consumed and urine and feces excreted were monitored daily. Food and water consumption as well as urine and feces excretion were monitored in mice caged in groups of three to five animals. On the final day, mice were anesthetized with ether, and blood was collected in a heparinized syringe by heart puncture. Plasma was collected after centrifugation $(5000 \mathrm{rpm}$ for $30 \mathrm{~min}$ at $4^{\circ} \mathrm{C}$ ) for biochemical analyses. The liver, kidneys, testes, and spleen were collected and weighed. The pancreas was fixed in Bouin's solution and subsequently histologically examined by the Taipei Institute of Pathology (Taipei, Taiwan) using Harris' hematoxylin and eosin (H\&E) staining method [23]. The pancreatic islets per section were counted from three different cross-sections.

\section{Biochemical Analysis}

For the blood biochemical analysis, a commercially available ELISA kit for insulin (Mercodia AB, Uppsala, Sweden) was used. Plasma chemistry (e.g., cholesterol and enzyme activity) tests were performed by Der-An Diagnostic (Jhong-li, Taiwan). Following the methods of Lee et al. [24], blood glucose levels were directly determined by a glucometer (Bayer Australia) using commercially available test strips for glucose.

\section{Statistical Analysis}

Data are expressed as the mean \pm SEM. Unpaired Student's $t$ test was used to examine differences among the normal and STZ-treated groups or among the STZ- and GSPC-treated groups. One-way ANOVA followed by the Student-Newman-Keuls multiple-range test was used to examine differences among multiple groups. Differences were considered significant at $\mathrm{P}<0.05$. Statistical analyses were performed using SigmaStat (Jandel Scientific, Palo Alto, CA, USA).

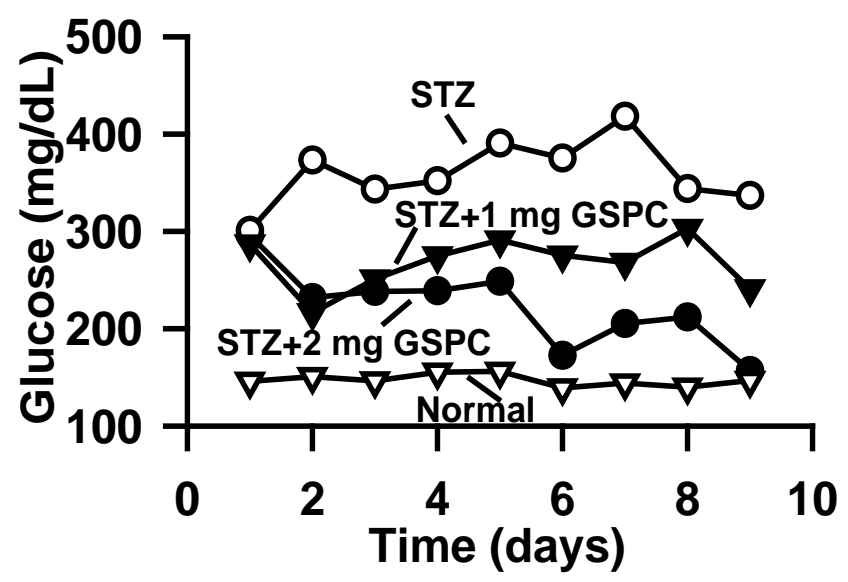

Fig. (1). The reduction by GSPC of STZ-increased blood glucose levels was dependent upon the dosage and duration of treatment. Decreased levels varied with the initial levels of blood glucose in mice with STZ-induced diabetes. Diabetes in $1 \mathrm{~d}$ fasting mice were induced by a single injection of $75 \mathrm{mg}$ of STZ for 3-7 d, and were then ip injected with 1 or $2 \mathrm{mg}$ of GSPC per mouse (40 or 80 $\mathrm{mg} / \mathrm{kg} \mathrm{BW}$ ) daily for $9 \mathrm{~d}$. Data are expressed as the means \pm SEM from five animals in each group. The SE bars are not shown for clarity. 


\section{RESULTS}

\section{Glucose Levels}

Intraperitoneal injections of GSPC caused decreases in blood glucose levels in mice with STZ-induced diabetes within $9 \mathrm{~d}$ of treatment (Fig. 1). The effect of GSPC was dependent upon the dosage and duration of treatment. A dose of $80 \mathrm{mg}$ of $\mathrm{GSPC} / \mathrm{kg}$ BW injected daily was significantly more effective at reducing blood glucose levels than was 40 $\mathrm{mg} / \mathrm{kg} \mathrm{BW}$.

In the experiments determining the values of GSPC (Fig. 1) required to significantly decrease blood glucose levels, we observed that the reduction in glucose levels was reversible; when GSPC administration was stopped, the reduced glucose levels rose (Fig. 2A). Further, these mice gradually adapted within $10 \mathrm{~d}$, and higher doses of GSPC ( 200 mg/kg BW) were needed to reduce the increased glucose levels (Fig. 2B).
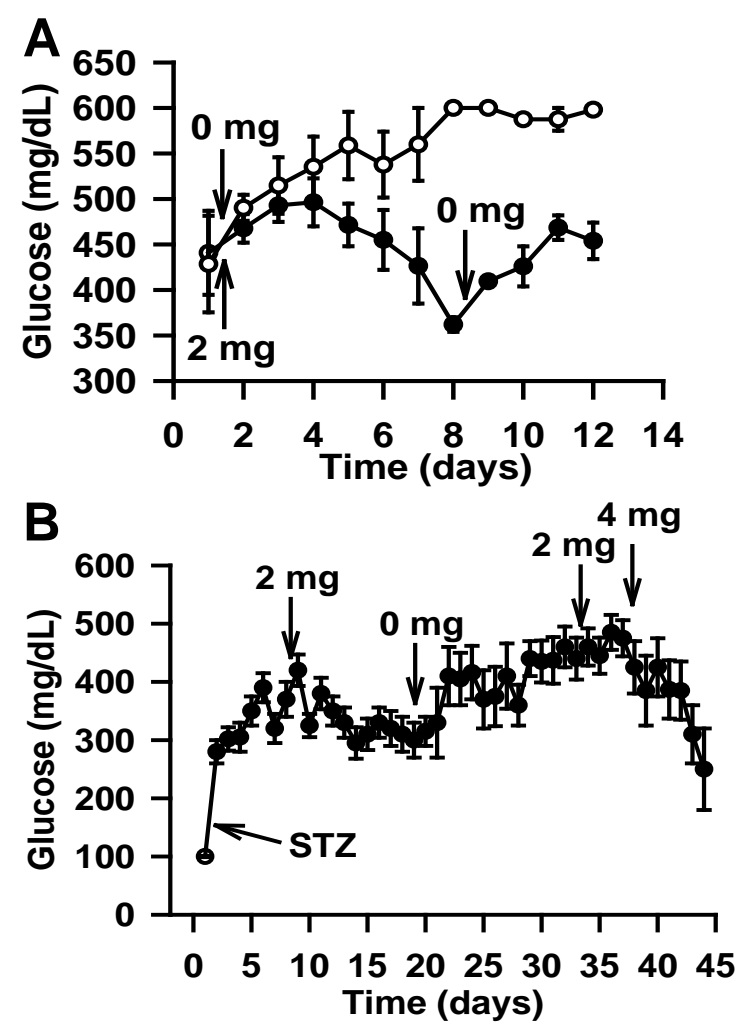

Fig. (2). Blood glucose levels in ICR mice with STZ-induced diabetes treated with GSPC. Mice with STZ-induced diabetes were ip injected daily with GSPC (number under arrow is the number of milligrams injected). Changes in the amount of GSPC injected are shown with arrows (A and B). Diabetic mice were injected with saline $(\bigcirc)$ or GSPC $(\mathbf{O})$. In (A), decreases in diabetic mouse blood glucose levels were reversible; when GSPC administration was stopped, glucose levels rose. In (B), mice gradually adapted within $10 \mathrm{~d}$, and higher doses (4 mg per mouse) of GSPC $(\sim 200 \mathrm{mg} / \mathrm{kg}$ $\mathrm{BW})$ were needed to reduce the increased glucose levels. Values are the means \pm SEM from five animals in each group.

To determine whether GSPC prevents diabetic induction by STZ in mice, we administered $80 \mathrm{mg}$ GSPC/ $\mathrm{kg}$ BW to normal mice (Fig. 3A), or they received no treatment (Fig. 3B). Seven days later, they were given a single injection of
$75 \mathrm{mg}$ of STZ/kg BW, and then provided daily with either GSPC or no treatment for an additional $10 \mathrm{~d}$. Although pretreatment with GSPC for $1 \mathrm{wk}$ did not completely prevent STZ-stimulated glucose levels in mice, it did rapidly reduce them within 2-10 d (Fig. 3A). In normal mice pretreated with GSPC or untreated for $1 \mathrm{wk}$, the mean values of blood glucose levels were maintained at approximately 130 157 $\mathrm{mg} / \mathrm{dL}$ or $151 \sim 174 \mathrm{mg} / \mathrm{dL}$, respectively; after $1 \mathrm{~d}$ of fasting, the respective mean glucose levels were 74 and $78 \mathrm{mg} / \mathrm{dL}$. When normal mice on an ad libitum diet were given two daily injections of GSPC for $10 \mathrm{~d}$, the mean glucose levels were in the range of 125 146 mg/dL, compared with those of control mice with a range of $153 \sim 179 \mathrm{mg} / \mathrm{dL}$. In contrast, when mice were not pretreated with GSPC but were simultaneously ip injected $7 \mathrm{~d}$ later with STZ for $10 \mathrm{~d}$ (Fig. 3B), at least $4 \mathrm{~d}$ of GSPC injection were required to significantly reduce blood glucose levels in STZ-injected mice. Normal mice treated with GSPC exhibited mean glucose levels of $169 \sim 183 \mathrm{mg} / \mathrm{dL}$ and a 1-d fasting mean glucose levels of 60 $\mathrm{mg} / \mathrm{dL}$. Following $10 \mathrm{~d}$ of GSPC injections, blood glucose levels changed to a range of $134 \sim 174 \mathrm{mg} / \mathrm{dL}$, compared with $150 \sim 187 \mathrm{mg} / \mathrm{dL}$ in control mice.
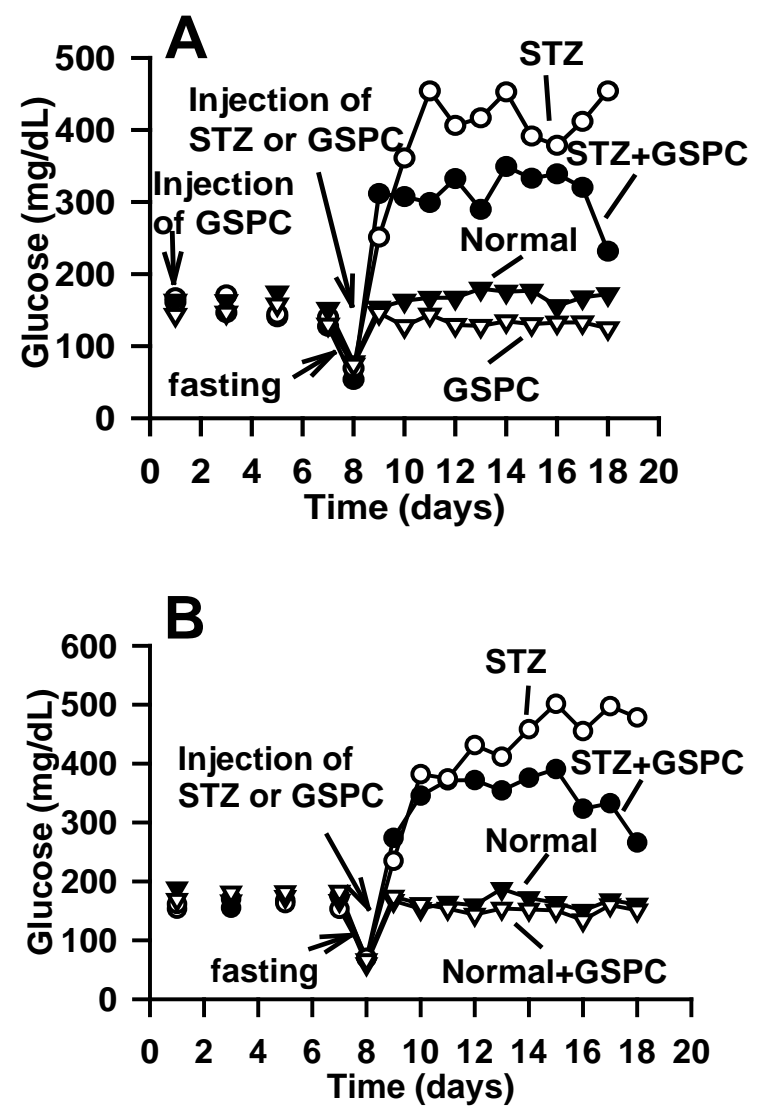

Fig. (3). GSPC rapidly decreased but did not completely prevent the stimulatory effect of STZ on blood glucose levels when normal mice were treated with GSPC ( $80 \mathrm{mg} / \mathrm{kg} \mathrm{BW}) 1 \mathrm{wk}$ before the STZ injection (A) or were given GSPC simultaneously with STZ (B). Data are expressed as the means \pm SEM from five animals in each group. The SE bars are not shown for clarity.

We next used $80 \mathrm{mg} \mathrm{GSPC} / \mathrm{kg} \mathrm{BW}$ to examine its affect on fasting glucose levels and oral glucose tolerance in mice 
with STZ-induced diabetes (Fig. 4). Mice with diabetes induced by a single injection of STZ were ip injected with 2 $\mathrm{mg}$ of GSPC $(=80 \mathrm{mg} / \mathrm{kg} \mathrm{BW})$ per mouse or were given no treatment for $7 \mathrm{~d}$. After $1 \mathrm{~d}$ of starvation, animals were orally administered a single dose of $1 \mathrm{~g}$ glucose $/ \mathrm{kg}$ BW and then monitored for $4 \mathrm{~h}$ (Fig. 4). We observed that the GSPC injection significantly reduced the 1-d fasting mean glucose levels in STZ-diabetic mice from 135 to $73 \mathrm{mg} / \mathrm{dL}$, which is close to the normal fasting glucose level of $64 \mathrm{mg} / \mathrm{dL}$. During the oral glucose tolerance test in normal mice, the rise in blood glucose levels produced by consuming the glucose solution was reduced to 106 and $72 \mathrm{mg} / \mathrm{dL}$, respectively, within $2 \mathrm{~h}$ and $4 \mathrm{~h}$ of glucose ingestion. In contrast, blood glucose concentrations remained at 271 and $122 \mathrm{mg} / \mathrm{dL}$, respectively, $2 \mathrm{~h}$ and $4 \mathrm{~h}$ after the oral glucose challenge in diabetic mice that did not receive GSPC injections, while they were 131 and 69 $\mathrm{mg} / \mathrm{dL}$ at $2 \mathrm{~h}$ and $4 \mathrm{~h}$, respectively, in mice with STZinduced diabetes treated with GSPC. Peak values of glucose levels in all groups of mice occurred $30 \mathrm{~min}$ after glucose ingestion, and were 165,361 , and $239 \mathrm{mg} / \mathrm{dL}$, respectively, in normal treated, diabetic untreated, and diabetic treated mice.

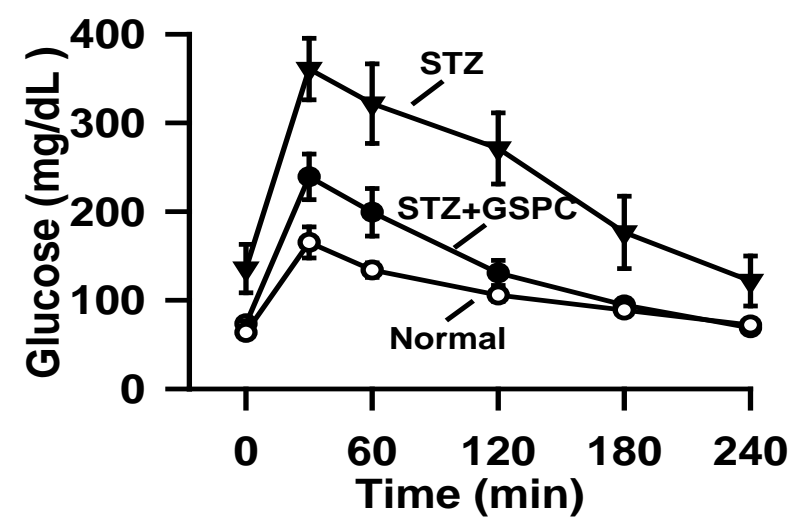

Fig. (4). GSPC improved the oral glucose tolerance in mice with STZ-induced diabetes. Mice with STZ-induced diabetes were ip injected daily with $80 \mathrm{mg} \mathrm{GSPC} / \mathrm{kg} \mathrm{BW}$ or were untreated for $7 \mathrm{~d}$. One day after the last treatment mice were fasted for $1 \mathrm{~d}$ and were then orally administered a single dose of $1 \mathrm{~g}$ glucose $/ \mathrm{kg} \mathrm{BW}$. Blood glucose levels were measured in intervals of 30 or $60 \mathrm{~min}$ for $4 \mathrm{~h}$. Data are expressed as the means \pm SEM from five animals in each group.

\section{Pancreatic Islets and Plasma Insulin Levels}

To investigate whether GSPC reduces the inhibitory effects of STZ on murine pancreas, we examined the histology of pancreatic islets using $\mathrm{H} \& \mathrm{E}$ staining methods (3), and measured changes in circulating levels of insulin (Fig. 5). We found that injection of $80 \mathrm{mg}$ of GSPC/ $\mathrm{kg}$ BW for $9 \mathrm{~d}$ markedly increased the mean weight of the pancreas in mice with STZ-induced diabetes from $1 \mathrm{mg}$ to $1.7 \mathrm{mg}$ (data not shown). Additionally, the number of pancreatic islets per tissue section in mice with STZ-induced diabetes was increased from $2.3 \pm 0.6$ to $4.3 \pm 0.8$ after an injection of $80 \mathrm{mg}$ GSPC $/ \mathrm{kg} \mathrm{BW}$, while those in normal mice without GSPC treatment were $10.8 \pm 1.7$ (Fig. $5 \mathbf{A}$ and $\mathbf{B}$ ). Finally, the mean circulating levels of insulin in mice with STZ-induced diabetes significantly increased from 0.29 to $0.61 \mathrm{ng} / \mathrm{ml}$ following
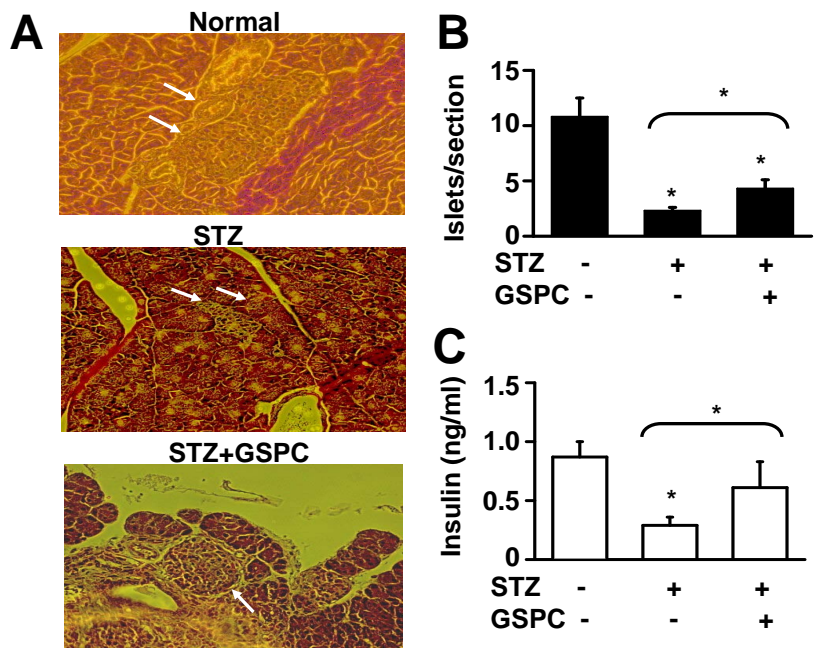

Fig. (5). GSPC reduced the suppressive effects of STZ on the number of pancreatic islets (A and B) and plasma insulin levels (C) in mice. Mice with STZ-induced diabetes were ip injected daily with $80 \mathrm{mg} \mathrm{GSPC} / \mathrm{kg} \mathrm{BW}$ or were untreated for $9 \mathrm{~d}$. The pancreas were microscopically examined using the H\&E staining method, while plasma insulin levels were examined with ELISA. Photos in (A) show representative histological sections. Data in $(\mathbf{B})$ and $(\mathbf{C})$ are expressed as the means \pm SEM from five animals per group.

an injection of $80 \mathrm{mg} \mathrm{GSPC} / \mathrm{kg} \mathrm{BW}$, compared with $0.87 \mathrm{ng}$ insulin/ml in normal mice without GSPC treatment (Fig. 5C).

\section{Other Blood Chemistry and Organs}

Mice with STZ-induced diabetes were treated with GSPC for $10 \mathrm{~d}$, and their plasma was analyzed for various components (Table 1). Treating normal mice with GSPC did not cause significant changes in plasma levels of total protein, albumin, triglyceride, blood urea nitrogen, creatinine, or enzymes that are indicative of severe damage to the liver and other organs, such as alanine aminotrasferase, aspartate aminotransferase, and lactate dehydrogenase. However, significant changes in the amount of blood cholesterol $(-39 \%)$ and the activity of blood alkaline phosphatase $(-28 \%)$ were observed. In contrast, treatment with STZ alone caused a significant decrease in the amount of blood albumin (-17\%), increased levels of blood triglyceride $(+25 \%)$ and creatinine $(+48 \%)$, and increased blood alkaline phosphatase activity (+98\%). Ten days after injection of $80 \mathrm{mg} \mathrm{GSPC} / \mathrm{kg} \mathrm{BW}$ into mice with STZ-induced diabetes, significant decreases in blood triglyceride (-21\%) and cholesterol (-27\%) levels and alkaline phosphatase activity $(-43 \%)$ were observed.

We next examined whether GSPC can reduce the inhibitory effect of STZ on the weight of murine liver, kidney, spleen, and testes (Table 2). In normal mice, the liver, kidneys, spleen, and testes did not exhibit any significant changes in organ weight $10 \mathrm{~d}$ after injecting $80 \mathrm{mg} \mathrm{GSPC} / \mathrm{kg}$ BW. However, treating mice with STZ alone tended to increase the weight of both the liver and kidneys compared with those of normal mice. Further, injecting $80 \mathrm{mg}$ but not $40 \mathrm{mg} \mathrm{GSPC} / \mathrm{kg}$ BW suppressed the STZ-increased weight of the liver and kidneys. 
Table 1. Effects of GSPC on Plasma Chemistry in Normal and STZ-Diabetic Mice

\begin{tabular}{|c|c|c|c|c|c|}
\hline Plasma/Organ & Normal & Normal+ GSPC ( 2 mg) & STZ & STZ+GSPC (1 mg) & STZ+GSPC (2 mg) \\
\hline Albumin $(g)$ & $2.4 \pm 0.1$ & $2.1 \pm 0.1$ & $2.0 \pm 0.1^{*}$ & $2.1 \pm 0.1$ & $1.9 \pm 0.1$ \\
\hline Triglyceride $(\mathrm{mg} / \mathrm{dL})$ & $114 \pm 10$ & $102 \pm 9$ & $143 \pm 14^{*}$ & $120 \pm 10$ & $113 \pm 17^{*}$ \\
\hline BUN (mg/dL) & $25 \pm 1$ & $24 \pm 1$ & $35 \pm 6$ & $36 \pm 3$ & $32 \pm 3$ \\
\hline Creatinine (mg/dL) & $0.29 \pm 0.02$ & $0.30 \pm 0.02$ & $0.43 \pm 0.02 *$ & $0.43 \pm 0.02$ & $0.38 \pm 03$ \\
\hline Uric acid $(\mathrm{mg} / \mathrm{dL})$ & $2.2 \pm 0.4$ & $1.8 \pm 0.3$ & $2.9 \pm 0.5$ & $2.9 \pm 0.3$ & $2.1 \pm 0.3$ \\
\hline ALT (U/L) & $103 \pm 24$ & $90 \pm 27$ & $183 \pm 64$ & $130 \pm 28$ & $181 \pm 42$ \\
\hline LDH (U/L) & $1606 \pm 173$ & $1968 \pm 391$ & $1951 \pm 368$ & $1455 \pm 178$ & $1784 \pm 220$ \\
\hline
\end{tabular}

The daily dose of GSPC per mouse injected ip was 1 or $2 \mathrm{mg}(\sim 40$ or $80 \mathrm{mg} / \mathrm{kg}$ BW) for $10 \mathrm{~d}$. Mice in normal group were injected with saline. Mice in STZ group were singly ip injected with $75 \mathrm{mg} / \mathrm{kg}$ BW. Values are the mean \pm SEM, $\mathrm{n}=8 .{ }^{*} P<0.05, \mathrm{GSPC} v s$. the normal group, STZ vs. the normalgroup,or GSPC + STZ $v s$. STZ. BUN, blood urea nitrogen ALT, alanine transaminase; AST, aspartate transaminase; ALKP, alkaline phosphatase; LDH, lactate dehydrogenase.

Table 2. Effects of GSPC on Organ Weight, Food Intake, and Water Consumption Innormal and STZ-Diabetic Mice

\begin{tabular}{|l|l|l|l|l|l|}
\hline Measurement & Normal & Normal+ GSPC (2 mg) & STZ & STZ+GSPC (1 mg) & STZ+GSPC (2 mg) \\
\hline \hline Initial BW (g) & $23.63 \pm 0.41$ & $23.30 \pm 0.62$ & $23.0 \pm 0.6$ & $23.1 \pm 0.2$ & $22.1 \pm 0.9$ \\
\hline Final BW (g) & $29.85 \pm 0.49$ & $26.50 \pm 0.81^{*}$ & $27.0 \pm 0.9^{*}$ & $24.2 \pm 0.2^{*}$ & $21.0 \pm 0.1^{*}$ \\
\hline Liver (g) & $1.81 \pm 0.05$ & $1.70 \pm 0.08$ & $2.0 \pm 0.06^{*}$ & $1.84 \pm 0.10$ & $1.77 \pm 0.08^{*}$ \\
\hline Kidney (g) & $0.57 \pm 0.04$ & $0.51 \pm 0.05$ & $0.62 \pm 0.02$ & $0.61 \pm 0.03$ & $0.54 \pm 0.02^{*}$ \\
\hline Spleen (g) & $0.17 \pm 0.01$ & $0.19 \pm 0.02$ & $0.16 \pm 0.01$ & $0.16 \pm 0.02$ & $0.15 \pm 0.01$ \\
\hline Testis (g) & $0.24 \pm 0.02$ & $0.21 \pm 0.02$ & $0.21 \pm 0.01$ & $0.23 \pm 0.02$ & $0.21 \pm 0.01$ \\
\hline Food (g/mice/day) & $4.95 \pm 0.16$ & $3.83 \pm 0.24 *$ & $7.00 \pm 0.30^{*}$ & $5.80 \pm 0.50^{*}$ & $4.75 \pm 0.31^{*}$ \\
\hline Water (g/mice/day) & $8.40 \pm 0.18$ & $6.00 \pm 0.40^{*}$ & $21.20 \pm 0.30^{*}$ & $13.7 \pm 2.42^{*}$ & $9.73 \pm 1.20^{*}$ \\
\hline
\end{tabular}

The daily dose of GSPC per mouse injected ip was 1 or $2 \mathrm{mg} \mathrm{(} \mathrm{40} \mathrm{or} 80 \mathrm{mg} / \mathrm{kg} \mathrm{BW})$ for $10 \mathrm{~d}$. Mice in normal group were injected with saline. Mice in STZ group were singly ip injected with $75 \mathrm{mg} / \mathrm{kg}$ BW. Values are the mean $\pm \mathrm{SEM}, \mathrm{n}=8 . * P<0.05$, GSPC $v s$. the normal group, STZ vs. the normal group, or GSPC + STZ vs. STZ.

Body Weight, Food and Water Intake, and Urine and Feces Excretion

Persistent thirst (polydipsia), frequent urination (polyuria), and nagging hunger (polyphagia) are common symptoms of diabetes [1]. Accordingly, we examined whether GSPC could regulate the effect of STZ on body weight, food and water consumption, and urine and feces excretion (Tables 2 and 3). Treating normal mice with $75 \mathrm{mg} \mathrm{STZ/kg}$ BW alone caused a significant decrease in body weight and significant increases in food intake and water consumption. Ten days after injection of 40 or $80 \mathrm{mg}$ GSPC $/ \mathrm{kg} \mathrm{BW}$, STZincreased food intake $(-17 \%$ and $-33 \%$, respectively) and water consumption $(-35 \%$ and $-54 \%$, respectively) was significantly suppressed, and STZ-induced decreases in body weight gain $(-10 \%$ and $-22 \%$, respectively) were also suppressed. Moreover, an ip injection of $80 \mathrm{mg} \mathrm{GSPC} / \mathrm{kg} \mathrm{BW}$ suppressed STZ-induced increases in urine and feces excretion by $78 \%$ and $41 \%$, respectively (Table 3 and Supplemental Fig. 1). Notably, injecting normal mice with $80 \mathrm{mg}$ GSPC/kg BW also caused significant decreases in body weight gain, food intake, and water consumption.

To determine whether GSPC depends upon the route of administration to mediate the effects of STZ on body weight, food and water intake and urine and feces excretion, we orally administered or ip injected mice with 90-100 mg GSPC/kg BW once daily for $10 \mathrm{~d}$ and then measured changes in these parameters (Table 3 ). The results of oral administration of GSPC were similar to those of GSPC ip injection with regard to suppressing STZ-increased blood glucose levels $(-28 \%)$, food $(-25 \%)$ and water $(-31 \%)$ consumption, urination $(-33 \%)$ and feces $(-44 \%)$ excretion, and enhancing the STZ-induced decrease in body weight $(-12 \%)$. 
Table 3. A Comparison of Orally and ip Administered GSPC on Glucose Levels, BW, Food and Water Intake, and Feces and Urine Excretion in STZ-Diabetic Mice

\begin{tabular}{|c|c|c|c|c|c|}
\hline Measurement & Normal & \multicolumn{2}{|l|}{ Oral } & \multicolumn{2}{|l|}{ ip } \\
\hline Glucose (mg/dL) & $168 \pm 7$ & $509 \pm 36$ & $368 \pm 3 *$ & $520 \pm 22$ & $298 \pm 46^{*}$ \\
\hline BW (g) & $29.0 \pm 1.7$ & $22.5 \pm 1.1$ & $19.7 \pm 0.1 *$ & $26.8 \pm 1.0$ & $20.5 \pm 0.1 *$ \\
\hline Food (g/mice/day) & $6.6 \pm 0.2$ & $6.8 \pm 0.3$ & $5.1 \pm 0.4^{*}$ & $7.4 \pm 0.3$ & $3.3 \pm 0.3 *$ \\
\hline Feces (g/mice/day) & $2.3 \pm 0.1$ & $3.4 \pm 0.3$ & $1.9 \pm 0.3 *$ & $2.7 \pm 0.2$ & $1.6 \pm 0.2 *$ \\
\hline Urine (g/mice/day) & $1.5 \pm 0.2$ & $8.1 \pm 0.5$ & $5.4 \pm 0.7 *$ & $6.7 \pm 0.8$ & $1.5 \pm 0.2 *$ \\
\hline
\end{tabular}

The daily dose of GSPC per mouse administered orally $(\sim 100 \mathrm{mg} / \mathrm{kg}$ BW) or ip $(\sim 90 \mathrm{mg} / \mathrm{kg}$ BW) was $2 \mathrm{mg}$ for $10 \mathrm{~d}$. Mice in STZ group were ip injected with $75 \mathrm{mg} / \mathrm{kg}$ BW.Values are the mean \pm SEM, $n=5$. The initial average values of plasma glucose measured in normal, oral (STZ and STZ+GSPC) and ip (STZ and STZ+GSPC) groups were $153 \pm 11,503 \pm$ $13,502 \pm 12,426 \pm 15$, and $423 \pm 13 \mathrm{mg} / \mathrm{dL}$, respectively. The initial average body weights of the normal, oral (STZ and STZ+GSPC) and ip (STZ and STZ+GSPC) groups were $20.7 \pm 1.0,19.5 \pm 0.7,19.8 \pm 1.2,22.7 \pm 0.6$, and $22.3 \pm 0.9 \mathrm{~g}$, respectively. $* P<0.05$, GSPC + STZ $v s$. STZ inoral or ipgroups.

Except for feces excretion, the changes in these parameters induced by oral GSPC intake were smaller than those induced by ip GSPC administration.

\section{DISCUSSION}

The present study describes how GSPC decreases diabetic symptoms induced by STZ in mice. The effects of GSPC were dose and time dependent. In general, concentrations exceeding $80 \mathrm{mg} / \mathrm{kg} \mathrm{BW}$ were more effective than a lower concentration of $40 \mathrm{mg} / \mathrm{kg} \mathrm{BW}$. Although the antidiabetic effects of GSPC on mice with STZ-induced diabetes were dependent upon the dosage and duration of treatment, the route of administration, and the presence of procyanidins, these results are similar to those observed previously in rats [13-14, 16, 19-20]. In our study, it is likely that GSPC decreased glucose levels in STZ-diabetic mice by increasing circulating insulin levels. This conclusion is supported by the findings that treatment with GSPC reduced STZ-decreased insulin levels and the number of pancreatic islets. Another possible explanation for the antidiabetic effect of GSPC is that it possesses antioxidant and free radical-scavenging activities [16-18] which reduce the destructive effect of the nitrosourea moiety of STZ on pancreatic islets. This explanation is indirectly supported by the fact that treatment with pycnogenol reduced the STZ-increased activity of hepatic catalase and elevated STZ-reduced levels of hepatic glutathione and glutathione redox enzyme activity [16]. The antioxidant and free-radical-scavenging properties of GSPC [16-18] may explain our findings that 1 -wk of pretreatment with GSPC caused an earlier decrease in diabetic glucose levels in mice with STZ-induced diabetes than did the simultaneous administration of STZ and GSPC (Fig. 3), which reduced glucose levels 1-2 d faster than did a post-STZ injection of GSPC (Fig. 1B).

In our study, GSPC suppressed STZ-stimulated food intake by mice. This observation is consistent with in vivo findings that the procyanidin-related polyphenol, (-)epigallocatechin gallate (EGCG), reduced food intake in obese Zucker rats [22] and Sprague-Dawley rats [26]. Thus, the effects of GSPC on the various diabetic symptoms of mice with STZ-induced diabetes may be secondary effect of GSPC on food intake. For example, the large decrease in urine and feces excretion in GSPC-treated STZ-diabetic mice could have been caused by diminished water consumption due to low food intake in these mice. Firm conclusions will require more thorough studies.

The GSPC used in this study consisted mostly of polyphenolic dimers of catechin and EC [10]. These grape seed polyphenols included $65 \%$ procyanidins, $30 \%$ catechin and EC monomers, $3 \%$ gallic acid, and $2 \%$ other compounds. Accordingly, we attempted to examine whether the polyphenolic monomers in the GSPC extract used in this study contributed to the suppression of the diabetic effects of STZ. Because amount of GSPC that had an antidiabetic effect was $2 \mathrm{mg}$ per mouse $(\sim 80 \mathrm{mg} / \mathrm{kg} \mathrm{BW})$, which should contain 0.6 $\mathrm{mg}$ catechin and EC and $0.06 \mathrm{mg}$ gallic acid, we used $0.5 \mathrm{mg}$ of each monomeric compound as the test concentration for daily ip administration to each mouse $(\sim 20 \mathrm{mg} / \mathrm{kg} \mathrm{BW})$. We found that when the monomers (i.e., catechin, EC, and gallic acid) were given individually to mice with STZ-induced diabetes for $9 \mathrm{~d}$, none of them alone significantly reduced STZinduced diabetic blood glucose levels after $8 \mathrm{~d}$ of treatment (data not shown). A combination of catechin and EC did not significantly alter blood glucose levels in STZ-injected mice, while the combination of catechin, EC, and gallic acid slightly reduced STZ-induced diabetic glucose levels by $10 \%$ (data not shown). However, neither EC nor gallic acid nor catechin caused significant changes in the circulating levels of insulin hormones or pancreas weight in mice with STZ-induced diabetes compared to mice treated with STZ alone (data not shown). Further, neither EC nor catechin nor gallic acid at the same concentrations and duration of treatment significantly decreased STZ-increased amounts of food intake, water consumed, or urine and feces excretions (data not shown). Taken together, these observations suggest that the effects of grape seed polyphenols on diabetic symptoms in mice with STZ-induced diabetes are due to procyanidins. This is consistent with previous findings that green tea modulates blood glucose levels in rats in polyphenol-specific ways [12], that the inhibitory effect of procyanidins on 12-Otetradecanoylphorbol-13-acetate-stimulated ornithine decarboxylase activity in mouse epidermis increases with the degree of polymerization (dimmers have a greater effect than monomers) [27], and that apple procyanidins inhibit pancre- 
atic lipase activity according to the degree of polymerization [28]. Procyanidin dimers contain a greater number of hydroxyl groups on the aromatic rings than do catechin or EC monomers, and these hydroxyl groups may be important for hydrogen bonding and free radical-scavenging activities [1618]. In addition, some GSPCs have more gallyl or galloyl group, which exhibit some conformational flexibility, and may also be important for interactions with other molecules. Further investigations of the chemical basis of the antidiabetic activity of GSPC in mice with STZ-induced diabetes are required to understand how procyanidin activity is different from that of EC and catechin.

The effects of GSPC on diabetic symptoms appear to depend upon the route administration. The effects of GSPC, like green tea EGCG [22], were weaker when a corresponding amount of GSPC was orally administered to mice for $9 \mathrm{~d}$. This may have been due to inefficient absorption of GSPC [29-31], and suggests that the effects of GSPC administered ip were not caused by interactions of between GSPC and food or by a reaction involving GSPC within the gastrointestinal tract.

The injected dose of GSPC (40-90 mg/kg BW) used in this study did not appear to be toxic to the liver or kidney of normal mice, because GSPC did not cause significant changes in the plasma levels of total protein, albumin, blood urea nitrogen, creatinine, uric acid, or enzymes that are indicative of severe damage to the liver and other organs. Furthermore, GSPC had no significant effect on the weights of mice liver and kidneys. Although we did not observe a statistically significant elevation of serum aspartate aminotransferase or lactate dehydrogenase activity in normal GSPCtreated mice, the small increase in the activities of these enzymes in the plasma could be indicative of a slight effect of GSPC on the liver, or could be related to lowered food intake. Significant changes in plasma alkaline phosphatase activity in normal GSPC-injected mice could also have been related to diet restriction. However, GSPC did not cause significant alterations in the number of pancreatic islets or circulating levels of insulin. In contrast, $80 \mathrm{mg} \mathrm{GSPC} / \mathrm{kg} \mathrm{BW}$ partially reduced the toxic effects of STZ on the liver and kidneys, as reflected by the fact that GSPC tended to reduce STZ-stimulated levels of plasma triglyceride, cholesterol, blood urea nitrogen, creatinine, uric acid, and alkaline phosphatase and lactate dehydrogenase activities, as well as the the STZ-stimulated weights of both the liver and kidneys. Decreased plasma triglyceride and cholesterol levels in mice with STZ-induced diabetes by GSPC may be attributable to the reduction in food intake and/or intestinal lipid absorption. This explanation is indirectly supported by reported findings that GSPC inhibits pancreatic lipase activity [28].

\section{CONCLUSION}

GSPC improve diabetic symptoms (e.g., increased urine and feces excretion; polyphagia; and blood glucose, triglyceride, and cholesterol levels) in mice with STZ-induced diabetes. Although oral administration of GSPC was less effective within $9 \mathrm{~d}$ than was ip administration of GSPC, longterm oral consumption of grape or procyanidin-containing extracts may mimic some of the acute GSPC effects described in this report and may be beneficial to health. The results of our study may provide some insight into the bene- ficial effects of procyanidin-containing beverages and the relationship between the high consumption of grapes and the low incidence of diabetes in some countries [10].

\section{ACKNOWLEDGMENTS}

We thank Jaden Polytechnic, Inc. (Greer, SC, USA) and Charlis Hsu for the gift of grape seed procyanidins. This work was supported by grants to Y.-H. Kao from the National Science Council, Taiwan (NSC95-2311-B-008-008MY3); the Armed Forces Tao-Yuan General Hospital, Taiwan; the Veteran General Hospital and University System of Taiwan Joint Research Program, and Tsou's Foundation, Taiwan; and the Cathay General Hospital and National Central University Joint Research Foundation, Taiwan.

\section{SUPPLEMENTARY MATERIAL}

Supplementary material can be viewed at www.bentham.org/open/tophyj

\section{REFERENCES}

[1] Besser MG, Thorner MO, Eds. Comprehensive Clinical Endocrinology. $3^{\text {rd }}$ edition, Mosby, an affiliate of Elsevier Science Ltd., Spain 2002.

[2] King H, Aubert RE, Herman WH. Global burden of diabetes, 19952005. Diabetes Care 1998; 21: 1414-31.

[3] Mokdad AH, Ford ES, Bowman BA, Nelson DE, et al. Diabetes trends in the US: 1990-1998. Diabetes Care 2000; 23: 1278-83.

[4] American Diabetes Association. Economic consequences of diabetes mellitus in the US in 1997. Diabetes Care 1998; 21: 296-309.

[5] Bloomgarden ZT. Diabetes and hypertension. Diabetes Care 2001; 24: $1679-84$

[6] Wannamethee SG, Shaper AG. Weight change and duration of overweight and obesity in the incidence of type 2 diabetes. Diabetes Care 1999; 22: 1266-72.

[7] Lotufo PA, Gaziano JM, Chae CU, Ajani UA, et al. Diabetes and all-cause and coronary heart disease mortality among US male physician. Arch Intern Med 2001; 161: 242-47.

[8] Rajala U, Laakso M, Qiao Q, Keinanen-Kiukaanniemi S. Prevalence of retinopathy in people with diabetes, impaired glucose tolerance, and normal glucose tolerance. Diabetes Care 1998; 21: 1664-69.

[9] Gu K, Cowie CC, Harris MI. Mortality in adults with and without diabetes in a national cohort of the US population, 1971-1993. Diabetes Care 1998; 21: 1138-45.

[10] Fine AM. Oligomeric proanthocyanidin complexes: history, structure, and phytopharmaceutical applications. Altern Med Rev 2000; 5: 144-51.

[11] Rusznyak S, Szent-Gyorgyi A. Vitamin P. flavanols as vitamins. Nature 1936; 138: 27.

[12] Pataki T, Bak I, Kovacs P, Bagchi D, et al. Grape seed proanthocyanidins improved cardiac recovery during reperfusion after ischemia in isolated rat hearts. Am J Clin Nutr 2002; 75: 894-9.

[13] Pinent M, Blay M, Blade MC, Salvado MJ, et al. Grape seedderived procyanidins have an antihyperglycemic effect in streptozotocin-induced diabetic rats and insulinomimetic activity in insulin-sensitive cell lines. Endocrinology 2004; 145: 4985-90.

[14] Pinent M, Blade MC, Salvado MJ, Blay M, et al. Procyanidin effects on adipocyte-related pathologies. Crit Rev Food Sci Nutr 2006; 46: 543-550.

[15] Tsuda T. Regulation of adipocyte function by anthocyanins: possibility of preventing the metabolic syndrome. J Agric Food Chem 2008; 56: 642-6.

[16] Maritim A, Dene BA, Sanders RA, Watkins III JB. Effects of pycnogenol treatment on oxidant stress in streptozotocin-induced diabetic rats. J Biochem Mol Toxicol 2003; 17: 193-9.

[17] Bagchi D, Bagchi M, Stohs SJ, Das DK, et al. Free radicals and grape seed proanthocyanidin extract: Importance in human health and disease prevention. Toxicology 2000; 148: 187-97.

[18] Bagchi D, Garg A, Krohn RL, Bagchi M, et al. Oxygen free radical scavenging abilities of vitamin $\mathrm{C}$ and vitamin $\mathrm{E}$ and a grape seed 
proanthocyanidin extract in vitro. Res Commun Mol Pathol Pharmacol 1997; 95: 179-89.

[19] Al-Awwadi N, Azay J, Poucheret P, Cassanas G, et al. Antidiabetic activity of red wine polyphenolic extract, ethanol, or both in streptozotocin-treated rats. J Agric Food Chem 2004; 52: 1008-16.

[20] Landrault N, Poucheret P, Azay J, Krosniak M, et al. Effect of a polyphenols-enriched chardonnay white wine in diabetic rats. J Agric Food Chem 2003; 51: 311-18.

[21] Junod A, Lambert AE, Orci L, Pictet R, et al. Studies of the diabetogenic action of streptozotocin. Proc Soc Exp Biol Med 1967; 126: 201-5.

[22] Kao YH, Hiipakka RA, Liao S. Modulation of endocrine systems and food intake by green tea epigallocatechin gallate. Endocrinology 2000; 141: 980-7.

[23] Ann Preece HT, Ed. A manual for histologic technicians. 3th edition. Little and Brown Company, Boston 1978.

[24] Lee MJ, Lin H, Liu CW, Wu MH, et al. Octylphenol stimulates resistin gene expression in 3T3-L1 adipocytes via the estrogen receptor and extracellularly-regulated kinase pathways. Am J Physiol Cell Physiol 2008; 294: 1542-51.

[25] Steppan CM, Bailey ST, Bhat S, Brown EJ, et al. The hormone resistin links obesity to diabetes. Nature 2001; 409: 307-12.
[26] Wu LY, Juan CC, Ho LT, Hsu YP, Hwang LS. Effect of green tea supplementation on insulin sensitivity in Sprague-Dawley rats. J Agric Food Chem 2004; 52: 643-8.

[27] Gali HU, Perchellet EM, Gao XM, Karchesy JJ, Perchellet JP. Comparison of the inhibitory effects of monomeric, dimeric, and trimeric procyanidins on the biochemical markers of skin tumor promotion in mouse epidermis in vivo. Planta Med 1994; 60: 235-9.

[28] Sugiyama H, Akazome Y, Shoji T, Yamaguchi A, et al. Oligomeric procyanidins in apple polyphenol are main active components for inhibition of pancreatic lipase and triglyceride absorption. J Agric Food Chem 2007; 55: 4604-9.

[29] Donovan JL, Manach C, Rios L, Morand C, et al. Procyanidins are not bioavailable in rats fed a single meal containing a grapeseed extract or the procyanidin dimer B3. Br J Nutr 2002; 87: 299-306.

[30] Nakamura Y, Tonogai Y. Metabolism of grape seed polyphenol in the rat. J Agric Food Chem 2003; 51: 7215-25.

[31] Tsang C, Auger C, Mullen W, Bornet A, et al. The absorption, metabolism and excretion of flavan-3-ols and procyanidins following the ingestion of a grape seed extract by rats. Br J Nutr 2005; 94: 170-81.

(C) Hsi et al.; Licensee Bentham Open.

This is an open access article licensed under the terms of the Creative Commons Attribution Non-Commercial License (http://creativecommons.org/licenses/by-nc/3.0/) which permits unrestricted, non-commercial use, distribution and reproduction in any medium, provided the work is properly cited. 